\title{
Vertical Water Velocities from Underwater Gliders
}

\author{
LuCAs MercKelbaCH, DAVID SMEED, AND GWYN GRIFFITHS
}

National Oceanography Centre, Southampton, Southampton, United Kingdom

(Manuscript received 30 April 2009, in final form 12 August 2009)

\begin{abstract}
The underwater glider is set to become an important platform for oceanographers to gather data within oceans. Gliders are usually equipped with a conductivity-temperature-depth (CTD) sensor, but a wide range of other sensors have been fitted to gliders.

In the present work, the authors aim at measuring the vertical water velocity. The vertical water velocity is obtained by subtracting the vertical glider velocity relative to the water from the vertical glider velocity relative to the water surface. The latter is obtained from the pressure sensor. For the former, a quasi-static model of planar glider flight is developed. The model requires three calibration parameters, the (parasite) drag coefficient, glider volume (at atmospheric pressure), and hull compressibility, which are found by minimizing a cost function based on the variance of the calculated vertical water velocity.

Vertical water velocities have been calculated from data gathered in the northwestern Mediterranean during the Gulf of Lions experiment, winter 2008. Although no direct comparison could be made with water velocities from an independent measurement technique, the authors show that, for two different heat loss regimes $\left(\approx 0\right.$ and $\approx 400 \mathrm{~W} \mathrm{~m}^{-2}$ ), the calculated vertical velocity scales are comparable with those expected for internal waves and active open ocean convection, respectively. High noise levels resulting from the pressure sensor require the water velocity time series to be low-pass filtered with a cutoff period of $80 \mathrm{~s}$. The absolute accuracy of the vertical water velocity is estimated at $\pm 4 \mathrm{~mm} \mathrm{~s}^{-1}$.
\end{abstract}

\section{Introduction}

Underwater gliders are set to become ubiquitous platforms for gathering data from within the oceans. Although a scientific vision for underwater gliders was painted by Stommel (1989), the technical and engineering concept for the current generation of vehicles came earlier, documented in the 1986 notebooks of Douglas Webb (Jones et al. 2005). Underwater gliders, or gliders for short, are buoyancy-engine-propelled autonomous underwater vehicles (AUV): they can attain positive or negative buoyancy to climb or sink, respectively. Being a torpedo-like shape and equipped with wings, vertical motion leads to a horizontal velocity, enabling a glider to traverse the oceans in a sawtooth way down to depths of 1000-1500 m. Using global positioning system (GPS) and two-way satellite communication systems, gliders can be controlled from shore. Usually gliders are equipped with conductivity-temperature-depth (CTD)

Corresponding author address: Lucas Merckelbach, National Oceanography Centre, Southampton, Empress Dock, SO14 3ZH, Southampton, United Kingdom.

E-mail:1mm@noc.soton.ac.uk sensors, but an increasing number of other sensors can be installed: for example, passive and simple active acoustic sensors, optical (backscatter and fluorescence) sensors, and chemical sensors. Currently, commercial gliders are available from three manufacturers: the Spray glider (Sherman et al. 2001), the Seaglider (Eriksen et al. 2001), and the Slocum glider (Jones et al. 2005).

During January-April 2008, three 1000-m-rated Slocum gliders of the National Oceanography Centre (NOC) were deployed off the coast of Toulon, France, to sample the western Mediterranean. The NOC gliders were part of a fleet of a total of nine gliders piloted from five European institutes [Laboratoire d'Océanographie et de Climatologie: Expérimentation et Analyse Numérique (LOCEAN; France); Institut Français de Recherche pour l'Exploitation de la Mer (IFREMER) Laboratoire de Physique des Océans (LPO; France); Leibniz-Institut für Meereswissenschaften (IFM-GEOMAR; Germany), Mediterranean Institute for Advanced Studies (IMEDEA; Spain) and NOC (United Kingdom)], under the umbrella of the European Glider Observatories (EGO) network.

The focus of the NOC gliders was to observe ocean convection during periods of intense heat loss that can occur in this region of the Mediterranean during winter 
(e.g., see Marshall and Schott 1999). Because convection is characterized by strong vertical fluxes of heat, not only CTD data but also information on vertical velocities are of scientific interest.

The vertical velocity of the water may be recovered from the glider's depth rate as measured by the pressure transducer if the motion of the glider relative to the water is measured or can be calculated. Because none of the gliders was equipped with instrumentation that measures the water velocity relative to the glider, the glider velocity through water needs to be modeled.

Under normal flight conditions the actuators for heading control (rudder for the Slocum and roll for Spray/ Seaglider) have little effect on the vertical motion of the glider. As the buoyancy and pitch control actuators (pump and sliding mass, respectively) operate only incidentally, most of the time the planar glider flight can be considered quasi-steady and feasibly modeled.

Sherman et al. (2001) have considered quasi-steady planar flight for the Spray glider and an extensive report on the glider dynamics, with application to the Slocum glider, is given by Graver (2005). The focus of the works mentioned is on defining glider design criteria. Research along similar lines has been done by Williams et al. (2007), where the focus is on the prediction of the performance of gliders. The main aim of this paper is to develop a quasi-static model of the dynamical behavior of the glider and a methodology of applying the model to data measured by a glider equipped with a CTD only to estimate vertical water velocities. In the present work, we focus on the Slocum glider, but the approach should also be applicable to other glider types. More sophisticated approaches using Kalman smoothing have been applied to other types of AUVs (e.g., Hayes and Morison 2002) and may be pursued in future work.

The paper is organized as follows: Section 2 presents relevant technical details of the glider used in this work and develops a quasi-static model of the glider. The parameters in the model are identified by applying the model to data gathered during the Gulf of Lions 2008 experiment in section 3 . Vertical water velocities that are calculated by the model are analyzed in section 4 .

\section{Glider model}

\section{a. Glider specifications}

The glider used is a Teledyne Webb Research Slocum Electric rated for 1000-m depth. Details and specifications of this glider can be found in Jones et al. (2005) and on the Web (available online at http://www.webbresearch. com/slocumglider.aspx). Here, we only mention the details that are relevant for this work.
The glider's propulsion system is a buoyancy engine, which has a maximum volume change of $\pm 270 \mathrm{~cm}^{3}$, which is also referred to as m_de_oil_vol. The CTD sensor on board is a Seabird SBE41 CTD (available online at http:// www.seabird.com/products/ModelList.htm; not pumped and modified for gliders). Although the SBE41 provides water pressure data, the water pressure data used herein are taken from the so-called flight pressure sensor (Micron MP50-2000; available online at http://www. microninstruments.com/store/mp5xseries.aspx). Although the CTD pressure sensor may be more accurate and may have a lower noise level, the flight pressure sensor is preferable for practical reasons, because it samples always at $0.25 \mathrm{~Hz}$, whereas the sample strategy for the CTD is constrained by scientific reasons and energy consumption considerations. The attitude (heading, pitch, and roll) is measured with a TCM3 (PNI Sensor Corporation) sensor (available online at http://www. pnicorp.com/products/all/tcm-legacy). The hulls of the 1000-m Slocum gliders are made of carbon fiber composite, as opposed to aluminum, which is used in other types of gliders. The fiber mats in the composite are woven at a particular angle such that the overall vehicle compressibility is slightly higher than the compressibility of seawater (roughly $5 \times 10^{-10} \mathrm{~Pa}^{-1}$ ), reducing the need to change buoyancy and therefore saving energy.

\section{b. Dynamic model of a glider for planar flight}

We consider a glider that moves as a solid body with respect to a patch of water, which itself moves with respect to an earth-fixed reference point. Setting up a twodimensional formulation (vertical plane) of the forces acting on the glider provides a framework that can be used to estimate planar flight of the glider in still water. Then, the difference in the estimated and measured vertical motions can be attributed to the vertical motion of the water mass the glider is flying in. A schematic representation of the gilder, the forces that work on it, and the definition of rotation angles are shown in Fig. 1. For the sake of clarity, all forces are schematized to originate from the center of gravity, which is permissible because a torque balance is not considered herein. Also note that the glide and pitch angles are positive when the glider points up, which is in accordance with the definition of pitch used in (Slocum) glider terminology.

Neglecting the acceleration terms is reasonable for motions with time scales greater than the time required for the vehicle to travel several body lengths. At a speed of $0.25 \mathrm{~m} \mathrm{~s}^{-1}$, the vehicle traverses 10 body lengths $(15 \mathrm{~m})$ in one minute; so, for time scales larger than one minute, we can consider the glider to be in quasi-steady flight. The vertical and horizontal force balances then read 


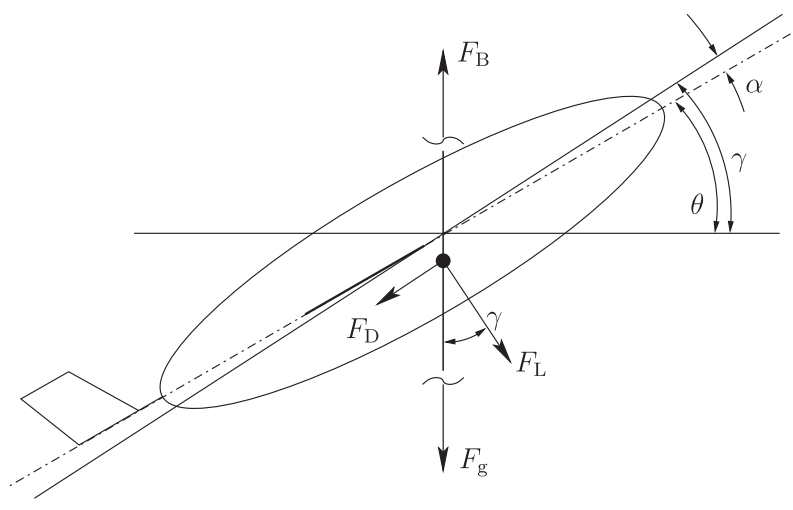

FIG. 1. Schematic representation of the glider moving in a vertical plane, the forces involved, and definition of angles. The forces working on the glider are buoyancy $F_{B}$, gravity $F_{g}$, lift $F_{L}$, and drag $F_{D}$. The difference between the glide angle $\gamma$ and the pitch $\theta$ is the angle of attack $\alpha$.

$$
\begin{gathered}
F_{B}-\cos \gamma F_{L}-\sin \gamma F_{D}-F_{g}=0 \quad \text { and } \\
\cos \gamma F_{D}+\sin \gamma F_{L}=0,
\end{gathered}
$$

respectively, where $F_{B}$ is the (net) buoyancy force; $F_{g}$ is the force due to gravity; $F_{L}$ is the lift force; $F_{D}$ is the drag force; and $\gamma$ is the glide angle, defined as the sum of the pitch angle $\theta$ and the angle of attack $\alpha$. Vertical force components resulting from the tail and rudder are neglected, which is reasonable, because the glider maintains largely a wings-level flight condition.

The force due to gravity is given by

$$
F_{g}=m_{g} g,
$$

where $m_{g}$ is the mass of the glider and $g$ the acceleration due to gravity. The net buoyancy force is given by

$$
F_{B}=g \rho\left\{V_{g}\left[1-\varepsilon P+\alpha_{T}\left(T-T_{0}\right)\right]+\Delta V_{\mathrm{bp}}\right\},
$$

where $\rho$ is the in situ density, $V_{g}$ is the glider volume at atmospheric pressure, $\varepsilon$ is the compressibility of the hull, $P$ is the water pressure, $\alpha_{T}$ is the thermal expansion coefficient, $T$ is the water temperature, $T_{0}$ is a reference water temperature, and $\Delta V_{\mathrm{bp}}$ the buoyancy change resulting from the buoyancy engine. The drag and lift forces are given by (e.g., Anderson 2005)

$$
\begin{aligned}
& F_{D}=\frac{1}{2} \rho C_{D} S U^{2} \text { and } \\
& F_{L}=\frac{1}{2} \rho C_{L} S U^{2},
\end{aligned}
$$

where $C_{D}$ and $C_{L}$ are the coefficients of drag and lift, respectively; $S$ is the wing surface area; and $U$ is the glider velocity through water along the glide path.

The total lift is modeled as the sum of the lift generated by the hull and the lift generated by the wings. Under normal flight conditions, the angle of attack is generally small (Eriksen et al. 2001). For small angles of attack, lift coefficient can be parameterized as

$$
C_{L}=\left(a_{h}+a_{w}\right) \alpha,
$$

where $a_{h}$ and $a_{w}$ are the lift-slope coefficients for the hull and wings, respectively. Williams et al. (2007) report on data of experiments determining the lift coefficient for a hull with the same dimensions and aspect as the Slocum glider. From their Fig. 9, in which the lift coefficient is plotted as function of the angle of attack, it appears that, for small angels of attack, $a_{h} \approx 3.1 \mathrm{rad}^{-1}$, with $C_{L}$ based on the frontal area of the hull $A_{h}$. With $C_{L}$ based on the wing area $(S)$, this corresponds to $a_{h} \approx 1.2 \mathrm{rad}^{-1}$, applying the factor $A_{h} / S=0.38$.

A semiempirical formula for the lift-slope coefficient is given by Etkin and Reid (1996, appendix B). The wings of a Slocum glider are swept-back thin plates. For the low speed the glider is flying at, the semiempirical formula, accounting for the lift reduction resulting from the wing sweep angle $\Omega$ and the aspect ratio AR, simplifies to

$$
a_{w}+\frac{2 \pi \mathrm{AR}}{2+\sqrt{\mathrm{AR}^{2}\left(1+\tan ^{2} \Omega\right)+4}} .
$$

The total drag is the combined effect of the parasite drag and induced drag, and it can be parameterized as

$$
C_{D}=C_{D_{0}}+C_{D_{1}} \alpha^{2},
$$

where $C_{D_{0}}$ is the parasite drag and $C_{D_{1}}$ is a coefficient determining the induced drag. Decomposing the total drag into drag to the hull and wings, respectively, we write $C_{D_{0}}=C_{D_{0}, h}+C_{D_{0}, w}$ and $C_{D_{1}}=C_{D_{1}, h}+C_{D_{1}, w}$. Williams et al. (2007) also report on experimental data for the drag coefficient of a hull similar to the Slocum glider (their Fig. 8), where the drag coefficient is plotted as function of the angle of attack. The data indicate that the profile (zero lift) and induced drag coefficients of the hull are $C_{D_{0}, h} \approx 0.15$ and $C_{D_{1}, h} \approx 5.5 \mathrm{rad}^{-2}$, respectively, again based on the frontal area of the hull. In terms of the wing area, this corresponds to $C_{D_{0}, h} \approx 0.06$ and $C_{D_{1}, h} \approx 2.1 \mathrm{rad}^{-2}$. The induced drag resulting from the wings can be parameterized as (e.g., Anderson 2005)

$$
C_{D_{1}, w}=\frac{a_{w}^{2}}{\pi \mathrm{ARe}},
$$


TABLE 1. Glider specific parameters for glider Coprolite. Note that the parameter $C_{D, h}$ is based on the wing area $S$, rather than the frontal area as reported in Williams et al. (2007).

\begin{tabular}{lcl}
\hline \hline Parameter & Value & Unit \\
\hline$S$ & 0.10 & $\mathrm{~m}^{2}$ \\
$\mathrm{AR}$ & 7 & - \\
$\Omega$ & 0.75 & $\mathrm{rad}$ \\
$A_{h}$ & 0.038 & $\mathrm{~m}$ \\
$m_{g}$ & 56.412 & $\mathrm{~kg}$ \\
$a_{w}$ & 3.7 & $\mathrm{rad}^{-1}$ \\
$C_{D_{1}, w}$ & 0.78 & $\mathrm{rad}^{-2}$ \\
$C_{D_{1}, h}$ & 2.1 & $\mathrm{rad}^{-2}$ \\
\hline
\end{tabular}

where $e$ is the span efficiency parameter $(e \approx 0.8)$.

Substituting (6) and (8) into (5) and (4), respectively, yields

$$
\begin{aligned}
& F_{D}=\frac{1}{2} \rho\left(C_{D_{0}}+C_{D_{1}} \alpha^{2}\right) S U^{2} \text { and } \\
& F_{L}=\frac{1}{2} \rho\left(a_{h}+a_{w}\right) \alpha S U^{2} .
\end{aligned}
$$

An implicit expression for the angle of attack is found by substituting (10) and (11) into the horizontal force balance (1b) and solving for $\alpha$,

$$
\alpha=\frac{C_{D_{0}}+\left(C_{D_{\mathrm{P}} w}+C_{D_{\mathrm{P}} h}\right) \alpha^{2}}{\left(a_{w}+a_{h}\right) \tan (\theta+\alpha)},
$$

from which $\alpha$ can be solved for numerically. Combining (1) and (10) gives

$$
\begin{aligned}
& F_{B}-F_{g}-\frac{1}{2} \rho S U^{2}\left[C_{D_{0}}+\left(C_{D_{1}, w}+C_{D_{\mathrm{r}} h}\right) \alpha^{2}\right] \\
& \quad \times \frac{\sin ^{2} \gamma-\cos ^{2} \gamma}{\sin \gamma}=0,
\end{aligned}
$$

from which, once $\alpha$ is solved for, $U$ can be evaluated. Then, the horizontal and vertical components of the velocity vector follow from

$$
\begin{aligned}
& u_{g}=U \cos (\theta+\alpha) \quad \text { and } \\
& w_{g}=U \sin (\theta+\alpha),
\end{aligned}
$$

respectively.

Equations (12)-(14) determine the quasi-steady velocity components for given (measured) forcing. The vertical velocity of the water $w$ then follows from the difference between the vertical velocity of the glider derived from the pressure rate $w_{p}$ and the modeled vertical velocity, reading

$$
w=w_{p}-w_{g}
$$

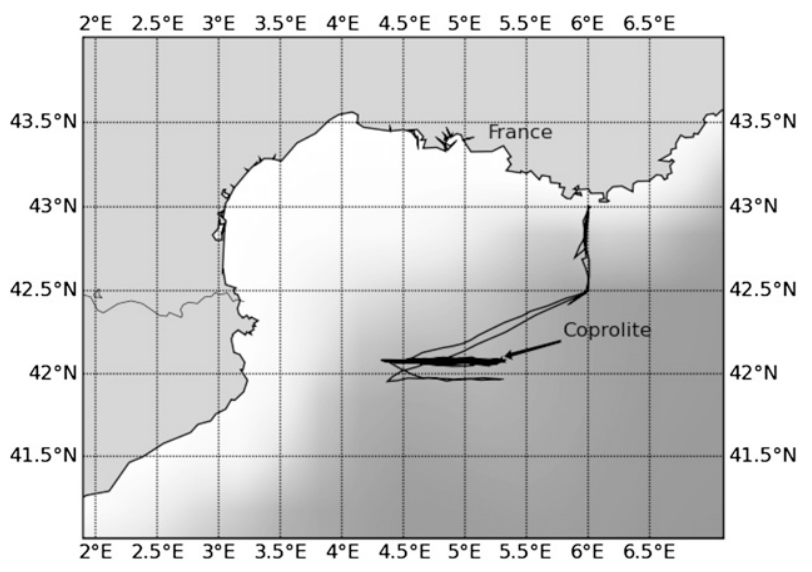

FIG. 2. Track of glider Coprolite during the Gulf of Lions 2008 experiment.

\section{Parameter calibration}

To evaluate the vertical velocity using Eqs. (12)-(15), a number of parameters need to be known. The sensor suite of the glider provides numerical input for $\theta, \Delta V_{\mathrm{bp}}$, $P$, and $\rho$. The glider specific parameters $S$, AR, and $m_{g}$ can be measured directly. ${ }^{1}$ Because the induced drag is a second-order effect and we cannot distinguish between the lift resulting from the hull and the wings, we use the parameterizations (7) and (9) and only the experimental value for $C_{D_{1 h}}$. Lumping the zero-lift drag resulting from the hull and protruding additions, such as the wings, CTD, and tail into a single parasite drag coefficient, leaves the parameters $C_{D_{0}}, \varepsilon, V_{g}, a_{h}$, and $\alpha_{T}$ to be identified. The values of all other parameters are listed in Table 1.

\section{a. Dataset: Gulf of Lions 2008}

To calibrate the model and assess its performance, the model is applied to data obtained during the Gulf of Lions 2008 measurement campaign. The parameter calibration procedure is shown for the NOC glider Coprolite (a Slocum 1000-m glider).

The glider Coprolite was deployed on 23 January 2008 and successfully recovered on 16 April, having traveled just over $2000 \mathrm{~km}$ (see Figs. 2, 3). During most of the mission, the glider was programmed to do a double yo dive cycle: a dive to $980 \mathrm{~m}$, a climb to $20 \mathrm{~m}$, again a dive to $980 \mathrm{~m}$, and resurface. At the surface $(\sim 20 \mathrm{~min})$ the glider tries to establish communications to transmit (a

\footnotetext{
${ }^{1}$ Measuring the glider mass (in air) requires a dedicated scale. Fortunately, the mass needs to be known only approximately, if the glider volume is left as a calibration parameter.
} 

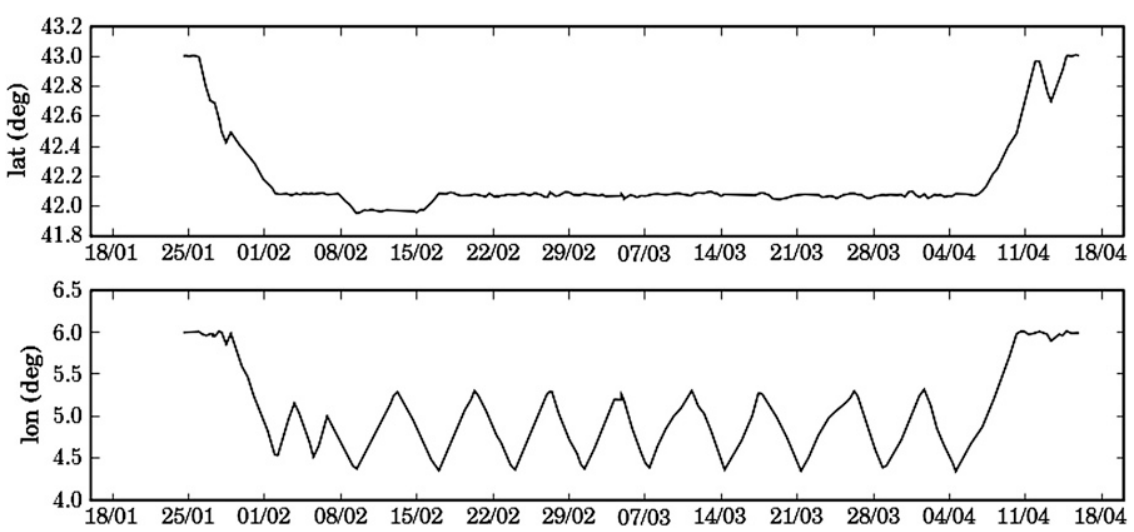

FIG. 3. GPS lat and lon as function of time for glider Coprolite.

subset of) measured data and optionally receive new operation instructions. A typical profile, obtained on 26 February, is presented in Fig. 4. The figure clearly shows the double yo pattern, which takes slightly over $7 \mathrm{~h}$ to complete. The (deliberately programmed) asymmetry in the oil volumes reflects the fact that the glider was ballasted slightly heavy. To save energy and reduce the number of sudden changes in the dynamics of the glider, most of the time the position of the pitch battery was kept constant during up and down casts, respectively. As a result, the measured pitch depends on the actual forces working on the glider. The pitch is seen to decrease during the up and down casts, which is the result of the buoyancy change of the glider resulting from the compressibility of the hull and the changing water density.

A summary of the glider state during the mission is shown in Fig. 5. It shows that initially the glider flew using maximum buoyancy change (speed $\approx 45 \mathrm{~cm} \mathrm{~s}^{-1}$ horizontally through water), but the buoyancy change was reduced to increase endurance after about two weeks when the glider arrived at the region of study (flying at $\approx 32 \mathrm{~cm} \mathrm{~s}^{-1}$ ). The speed was increased again at the end of the mission on its way back to the recovery location near Toulon, France.

Most of the time, the pitch was controlled with the pitch battery set at a fixed position for the up and down casts, respectively. The exceptions are a few dive cycles at the beginning of the mission and after each change in buoyancy when the glider was used in a mode whereby a servo controlled the pitch battery position to maintain dive angles of $26^{\circ}$. Data from these dives were used to determine the positions to fix the pitch battery at during the following dives.

Salinity and potential temperature data are shown in Fig. 6. Near the coast (begin and end of the mission), the water column is reasonably stratified; further offshore, however, differences in salinity and temperature are generally small. The linear coefficient of thermal expansion of carbon fiber composite is on the order of $10^{-5}{ }^{\circ} \mathrm{C}^{-1}$, so that, with temperature differences on the order of a degree, the effect of thermal expansion on the volume of the glider is about $1 \mathrm{ml}$. Although the effect becomes significant for a glider in an environment with strong thermoclines, for the present application, the

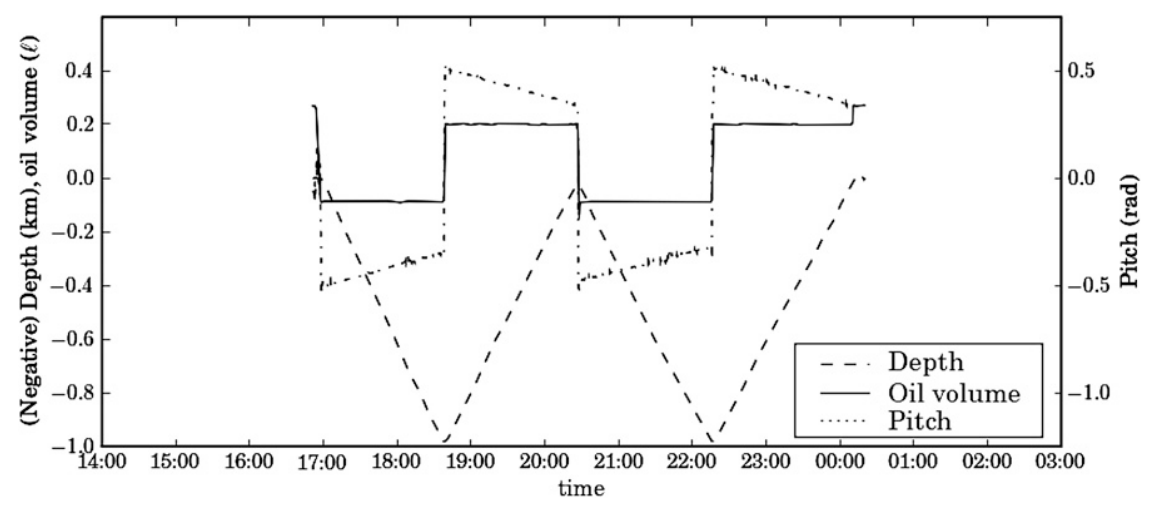

FIG. 4. Typical profile data from Coprolite, measured on 26 Feb 2008: pitch battery has been preset and kept constant during the up and down casts, respectively. 


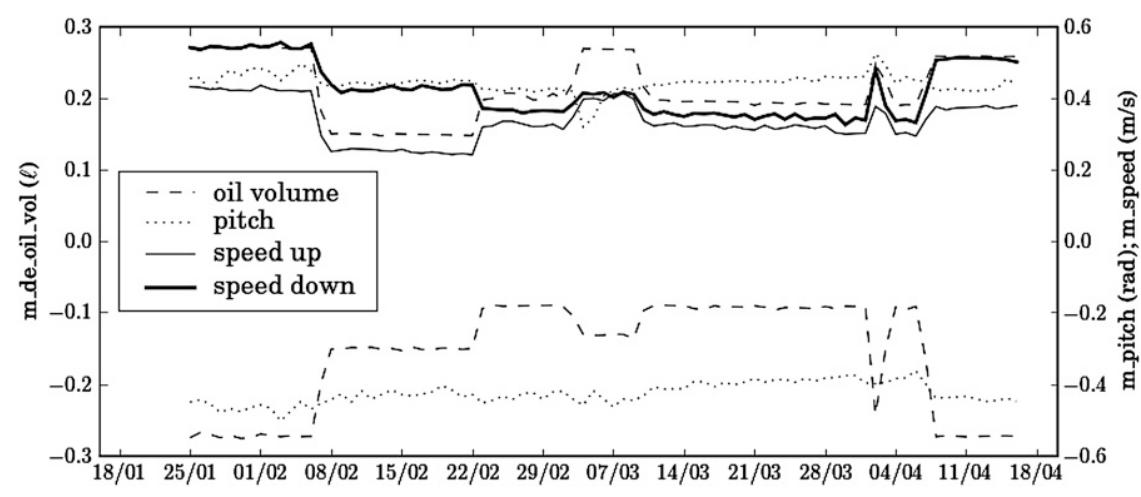

FIG. 5. Summary of flight data: envelopes of measured buoyancy change (dashed line), measured pitch (dotted line), horizontal glider speed during up casts (thin solid line), and horizontal glider speed during down casts (thick solid line).

thermal expansion effects are insignificant and therefore not considered further.

\section{b. Parameter identification by minimizing cost function}

To calibrate the parameters $C_{D_{0}}, \varepsilon, V_{g}$, and $a_{h}$, we assume that over a sufficient amount of time the mean difference between the observed vertical velocity (derived from pressure sensor output) and the modeled vertical velocity is zero for the correct parameter setting. Then, $C_{D_{0}}, \varepsilon, V_{g}$, and $a_{h}$ can be estimated by applying a search method to minimize a cost function $F$.

The minimization process is likely to converge if each of the calibration parameters has a distinct effect on $F$. An increase in $C_{D_{0}}$ results in a reduction of the magnitude of the modeled velocity in both the up and down casts. An increase in $V_{g}$ results in an increase of buoyancy (uniform with depth), decreasing the magnitude of the modeled velocity on the down cast but the reverse on the up cast. An increase in $\varepsilon$ results in a decrease of buoyancy with depth; consequently, the magnitude of the modeled velocity will increase with depth on the down cast but decrease with depth on the up cast.

From (12) and (13), it can be seen that $a_{h}$ enters the equation through the angle of attack and with that also through the pitch. The glider is typically flown with a movable mass constantly controlling the pitch during flight or, to conserve energy, with the movable mass fixed at certain positions for each up and down casts. In the former case, the pitch is more or less constant, whereas, in the latter case, the pitch varies with depth (Fig. 4). Consequently, the effect of $a_{h}$ cannot be distinguished from the effects of $C_{D_{0}}$ and $\varepsilon$, so that $a_{h}$ is not included in the minimization function. Thus, the minimization function $F$ is defined as

$$
F=\sum_{i}^{N}\left[w_{p}^{2}-w_{g}\left(C_{D_{0}}, \varepsilon, V_{g}\right)^{2}\right]
$$

where $N$ is the number of data points used in the minimization process.
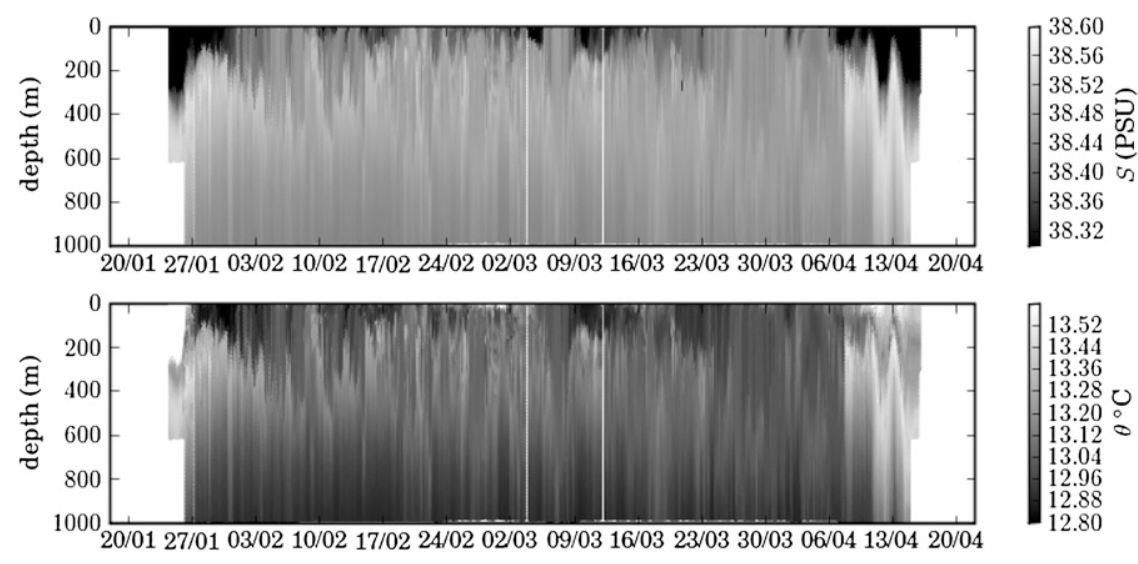

FIG. 6. (top) Salinity and (bottom) potential temperature profiles. 
(a)

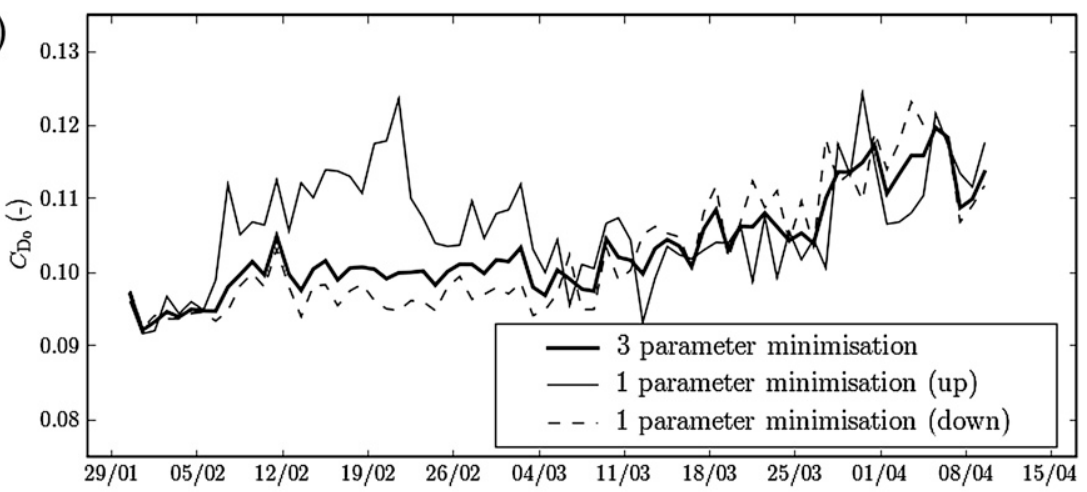

(b)

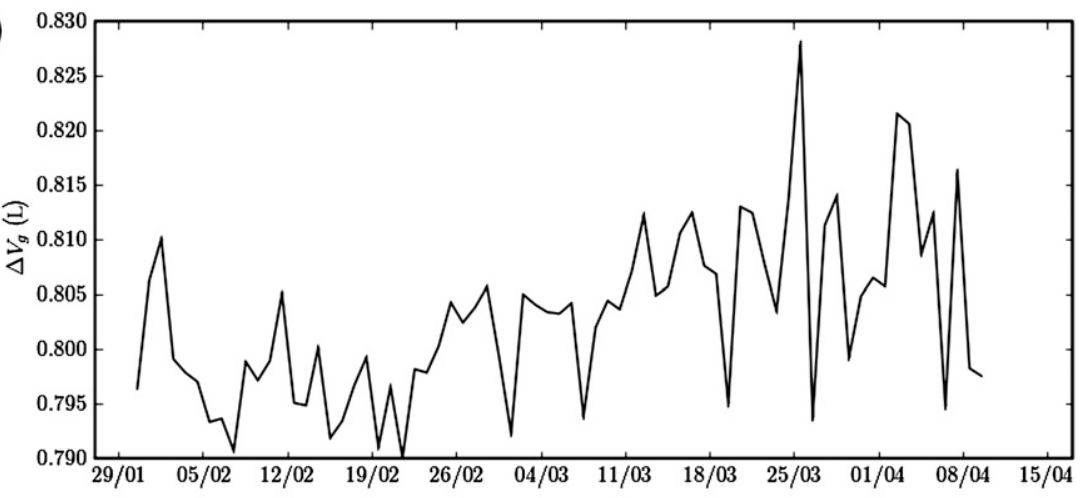

(c)

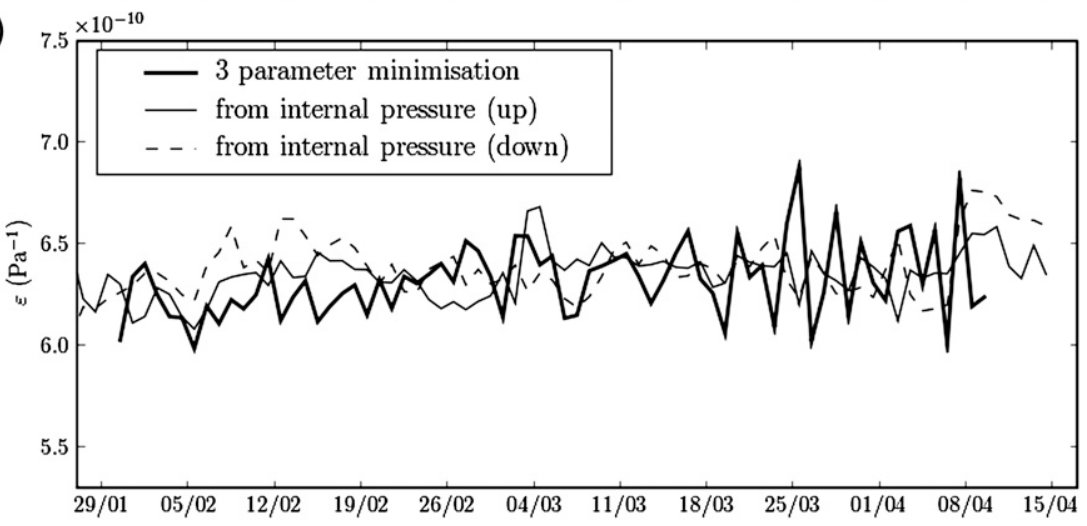

FIG. 7. Results of the minimization procedure for glider Coprolite: (top) drag coefficient; (middle) glider volume, reduced by $54 \mathrm{~L}$; and (bottom) vehicle compressibility.

The choice of $N$ in the cost function reflects the length of time over which we expect the vertical velocity to average to zero. Here, we are interested in processes with time scales up to a few hours, so we use a cost function that is an average over one day or more.

Anticipating the result in next subsection, we set $a_{h}=$ $2.4 \mathrm{rad}^{-1}$, rather than $a_{h}=1.2 \mathrm{rad}^{-1}$ as reported by Williams et al. (2007), and apply a standard nonlinear search method to minimize the cost function (16) to all available data split up in 1-day segments. The resulting estimates for $C_{D_{0}}, V_{g}$, and $\varepsilon$ are shown in Fig. 7. The thick solid line in the top panel shows the estimate of the drag coefficient, which is about 0.10 . This value is a bit larger than the experimental value found for the hull alone $\left(C_{D_{0}, h}=0.06\right)$, which is to be expected, because the experimental value does not include protrusions as the CTD, wings, and tail. Interestingly, the drag coefficient is seen to increase with time. This may be due to biofouling. However, at particular times, sudden changes occur, namely around 7 February and later around 8 April, where the drag first increases and then decreases again. From the engineering data shown in Fig. 5, it appears that these sudden changes coincide with changes in buoyancy drive. The observed changes could relate to changing Reynolds numbers, as suggested by Graver (2005). 
The glider volume is presented in the middle panel as $\Delta V_{g}$, where $\Delta V_{g}=V_{g}-54 \mathrm{~L}$. A priori, one would expect the volume to be constant, because the deformation resulting from compression is assumed to be elastic (and dealt with separately). Nevertheless, the minimization procedure finds fairly large fluctuations on the order of $10 \%$ of the maximum buoyancy drive with respect to neutral. Assuming the buoyancy force $\propto$ velocity squared, this corresponds to a $1-2 \mathrm{~cm} \mathrm{~s}^{-1}$ error in vertical velocity.

The change of the external oil volume, which is the de facto buoyancy change, is inferred from the measured volume change of the internal reservoir. If air bubbles are present in the oil system, then the volume of air inside the internal reservoir has left an equal volume of oil in the external reservoir. This causes the glider to have more buoyancy than inferred from the measurement. If air can move between the internal and external reservoirs, the difference between measured (inferred) and real buoyancy can be highly variable with time. It could be that the variation found in the glider volume estimate is related to air inside the oil system (see also Griffiths et al. 2007).

The engineering data in Fig. 5 also indicate that air was inside the oil system. The best example is probably the period from 10 to 31 March. During this period, the commanded oil volume change has not altered. Still, the measured oil volume seems to decrease with time for the up casts, but not for the down casts. The technical explanation for this is that, at the moment the buoyancy is commanded to be increased (at depth), the internal reservoir is pressurized to $200 \mathrm{kPa}$ (C. Jones 2008, personal communication) to assist the oil pump. Upon reaching the target oil volume, the pump is switched off and the pressure is released. Air inside the internal reservoir will expand; therefore, the volume of the internal reservoir will increase. The glider reports this as a drop in the (external) oil volume measurement. The effect is not visible for the down cast because, when oil is let from the external to the internal volume, no pressurization of the internal reservoir is required and the internal volume will not change upon reaching the target volume. Because it is difficult to establish how much air is inside the oil system and how it is distributed between the internal and external reservoirs, we do not try to quantify this effect. However, it seems very likely that minimizing the cost function translates the time-varying discrepancy between the inferred and real buoyancy to variations in the drag coefficient and glider volume to compensate.

The third parameter that is estimated from the minimization procedure is the compressibility, shown in the bottom panel of Fig. 5 by the thick solid line. Like the glider volume, the compressibility is expected to be constant with time. The average value is about $6.4 \times$ $10^{-10} \mathrm{~Pa}^{-1}$, which is close to that of seawater $(\approx 5 \times$ $\left.10^{-10} \mathrm{~Pa}^{-1}\right)$. The fluctuations correspond to an amount of about $5 \mathrm{cc}$, which is considered acceptable. The presence of air inside the oil system may affect the compressibility of the oil. A weak positive correlation between the glider volume and compressibility seems to exist, suggesting that, the more oil in the external volume, the more compressible the glider appears.

Because the glider volume and the compressibility are expected to be constant, the minimization procedure can be done for the up and down casts separately, optimizing for the drag coefficient and presetting the glider volume and compressibility with a constant value. Taking the glider volume and compressibility equal to $54.802 \mathrm{~L}$ and $6.4 \times 10^{-10} \mathrm{~Pa}^{-1}$, respectively, yields the drag coefficients for the up and down casts shown in the top panel of Fig. 7 by the (thin) solid and dashed lines, respectively. In effect, this minimization procedure compensates for fluctuations in the glider volume through the drag coefficients for the up and down casts separately. Where the glider volume in the second panel equals the preset glider volume value of $54.802 \mathrm{~L}$, the drag coefficients for the up and down casts are the same; when the fitted glider volume is larger than the preset value, the drag on the up casts reduces (to increase the modeled speed on the up cast), and the drag on the down casts increases (to reduce the modeled speed). A similar argument applies when the glider volume is smaller than the preset value.

In conclusion, the parameters found for $C_{D_{0}}, V_{g}$, and $\varepsilon$ are within the expected range, but the drag coefficient and the glider volume show a fair amount of variation. A key issue to address is whether the observed fluctuations in the parameters real; artifacts of the underlying model used; or caused by errors from the input data, which is the case if air bubbles are present in the oil system.

Shallow Slocum gliders (maximum diving depth $200 \mathrm{~m}$ ) use a piston to change their buoyancy; as a result, the buoyancy change measurement does not suffer from uncertainties resulting from air bubbles. Applying the same procedure to the shallow Slocum glider Pytheas, which was operated in the same period by LOCEAN, Paris, France, it is seen (Fig. 8) that the drag coefficient gradually increases from about 0.09 to 0.13 , which is significantly more than the increase in drag observed for the glider Coprolite. Because the shallow glider spent much more time in shallow and biological active water layers, the stronger increase in drag with time may well be explained by biofouling. The case for biofouling is strengthened by the observation that both the shallow and the deep glider appear to experience an extensive 


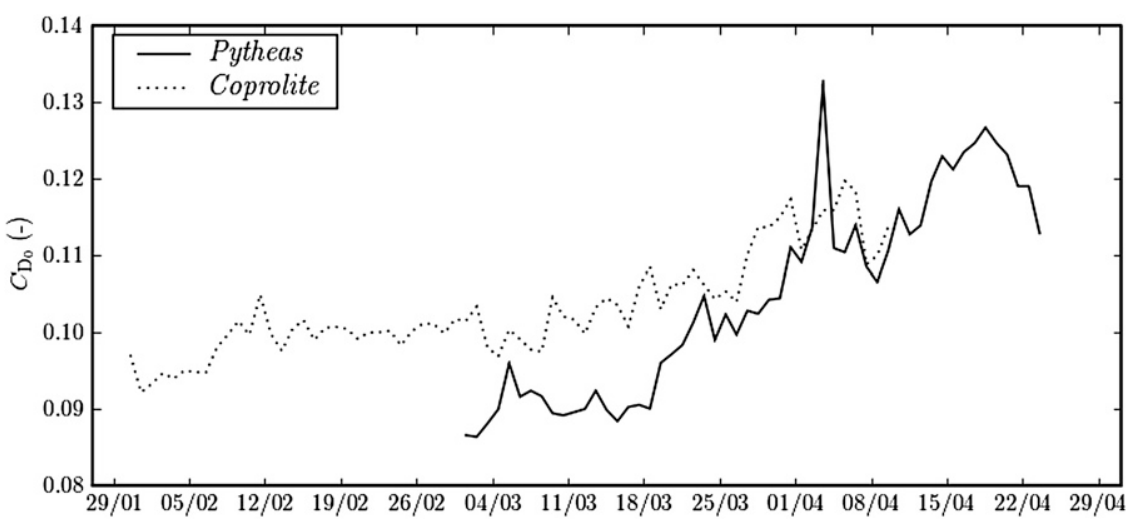

FIG. 8. The drag coefficient resulting from the minimization procedure for gliders Pytheas (solid line) and Coprolite (dotted line). Data of Pytheas were provided by courtesy of P. Testor and L. Mortier (2009, LOCEAN, personal communication).

period during which the drag increases more or less linearly with time, commencing in both cases around 15 March. Upon recovery of glider Coprolite only a few fouling organisms were found; however, the hull was patched with a thin, slime-like film, which may have been sufficient to account for the (apparent) increase in parasite drag.

Ideally, the modeled velocities would be compared with measured velocities, but these were not measured for technical and practical reasons. It is possible, however, to estimate the drag coefficient and vehicle compressibility in an independent way. In section 4, the calculated vertical water velocity data are analyzed in detail and judged to what extent they are realistic.

\section{c. Lift coefficient hull}

While under water, the glider's position can be estimated using a dead-reckoning algorithm. The magnitude of the horizontal velocity is calculated from the vertical velocity deduced from the pressure sensor $w_{p}$ by

$$
u_{\mathrm{dr}}=\frac{w_{p}}{\tan (\theta+\alpha)}
$$

The dead-reckoned position follows from integrating the horizontal velocity with respect to time, taking into account the measured heading. Because the real position of the glider is known prior to diving and upon resurfacing from GPS, the difference between the deadreckoned and GPS surfacing positions, divided by the subsurface time yields, for each segment (i.e., from diving to resurfacing), an observed depth-averaged current $U_{\text {obs. }}$. The parameter $E_{u}$ is introduced which represents the weighed average of the observed current as function of time $t$, given by

$$
E_{u}\left(t_{n}\right)=\frac{1}{L} \sum_{0}^{i=n} U_{\mathrm{obs}, i} \Delta L_{i},
$$

where $i$ refers to the segment number, $L_{i}$ is the length of each segment, and $L$ is the total distance traveled (i.e., $\left.L=\sum_{0}^{i=n} \Delta L_{i}\right)$. The observed current for a particular segment $\boldsymbol{S}$ can be written as

$$
U_{\mathrm{obs}}=\frac{1}{|\boldsymbol{S}|}\left[\int_{\boldsymbol{S}^{\prime}} \boldsymbol{U}_{\mathrm{c}} \cdot d \boldsymbol{s}+\int_{\boldsymbol{S}} \boldsymbol{U}_{\mathrm{e}} \cdot d \boldsymbol{s}\right]
$$

where $\boldsymbol{U}_{\mathrm{c}}$ is the real current and $\boldsymbol{U}_{\mathrm{e}}$ is an artificial current resulting from an erroneous dead-reckoning procedure. If the depth-averaged ocean current can be considered constant and uniform, then the first term of the righthand side (rhs) of (19) evaluates to zero for a closed path, such as a rectangular trajectory or a trajectory going back and forth between two waypoints. Then $E_{u}$ represents the bias in horizontal glider velocity into the direction of flight. For such a closed trajectory, the angle of attack can be changed by tuning the lift-slope coefficient for the hull so that $E_{u}$ vanishes.

The parameter $E_{u}$ is shown in Fig. 9, calculated for the period of 20 February to 1 April. During this period the glider flew six times back and forth along an east-west trajectory, so that its trajectory can be considered a closed path, see also Fig. 3. The (thin) solid line shows the bias in horizontal velocity for $a_{h}=1.2 \mathrm{rad}^{-1}$ (as experimentally found) and the corresponding optimized settings for $C_{D}$, $V_{g}$ and $\varepsilon$. It is seen that the bias in the horizontal velocity approaches a value of about $-0.01 \mathrm{~m} \mathrm{~s}^{-1}$, i.e., the model calculates a horizontal velocity component that is too low and thus an angle of attack that is too large. Reducing the angle of attack by increasing the lift slope $a_{h}$ to $2.4 \mathrm{rad}^{-1}$ and repeating the optimization procedure yields the bias 


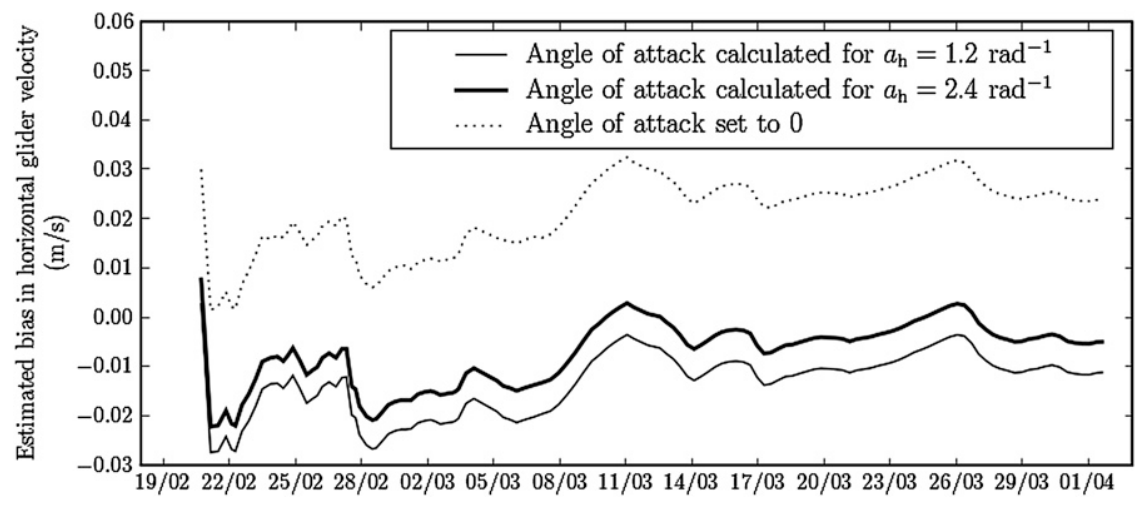

FIG. 9. Estimated bias in horizontal glider velocity in the direction of flight.

in horizontal velocity shown by the thick line. As can be seen, the bias for this setting more or less vanishes. The value for $a_{h}$ is twice the value reported by Williams et al. (2007). An explanation for this can be that, in comparison with the experiments, extra lift is generated by the tail, which has a horizontal disk housing the communications antennae, and because of the interaction between the lift effects of the wings and hull.

For the case that the angle of attack is set to zero in (17), as currently is the case in the dead-reckoning algorithm of the Slocum glider, the bias in horizontal velocity is about $0.03 \mathrm{~m} \mathrm{~s}^{-1}$, as is shown by the dotted curve. With ocean currents being on the order of 0.1$0.2 \mathrm{~m} \mathrm{~s}^{-1}$, this means that current estimates as calculated by the glider's algorithm need to be corrected for this artificial horizontal velocity component.

\section{d. Vehicle compressibility}

We consider a schematized glider geometry as depicted in Fig. 10. The front cap, which houses the oil volume system, consists of thick-walled aluminum, which is estimated to be 10-20 times less compressible than water. Similarly, the end cap and tail boom are made of solid aluminum and stainless steel, respectively, and can be assumed not to compress. The carbon fiber hull sections (hashed) are assumed to compress mainly in the longitudinal direction.

Denoting $z$ as the vertical coordinate, taken positive in the downward direction, the volume change with depth is given by

$$
\frac{d V_{g}}{d z}=-V_{g} \rho g \varepsilon
$$

[see also (3)]. The volume of the glider can be decomposed into

$$
V_{g}=V_{c}+V_{i}+V_{h}
$$

where $V_{c}$ is a constant volume, consisting of incompressible parts and the internal hardware, which is not subjected to significant pressure changes; $V_{i}$ is the internal air volume; and $V_{h}$ is the volume taken up by the compressible hulls. Solving for $V_{i}$ and differentiating the result with respect to $z$ yields

$$
\frac{d V_{i}}{d z}=\frac{d}{d z}\left(V_{g}-V_{h}\right)
$$

Because the compression of the hull sections is mainly longitudinal (and other external parts are considered incompressible),

$$
\frac{d V_{h}}{d z}=-V_{h} \rho g \varepsilon
$$

Note that, because of assumptions made earlier, the coefficient of compressibility in (23) takes the same value as the coefficient in (20). Substituting (23) and (20) into (22) gives the change of internal air volume with depth

$$
\frac{d V_{i}}{d z}=-\left(V_{g}-V_{h}\right) \rho g \varepsilon
$$

The internal air is assumed to behave as an ideal gas: that is, $P_{i} V_{i} / T_{i}=$ constant, where $P_{i}$ is the absolute internal pressure, $V_{i}$ is the internal air volume, and $T_{i}$ is the

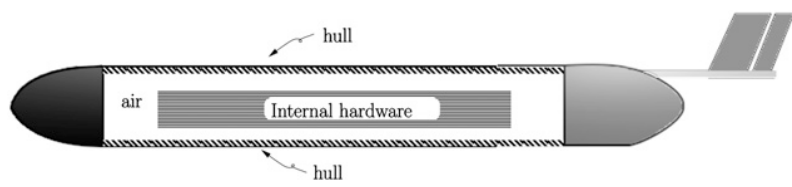

FIG. 10. Longitudinal cross section of a glider: The carbon fiber hull sections (hashed) are designed to compress in the longitudinal direction. The front and end caps, as well as the internal hardware, are assumed to be incompressible. 


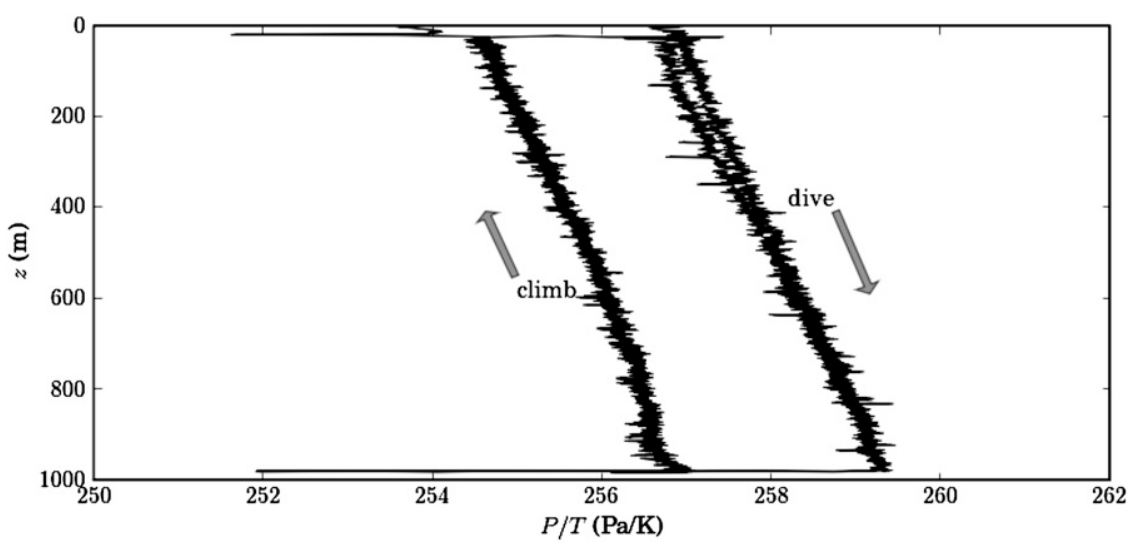

FIG. 11. $P / T$ as function of $z$ for a complete dive cycle.

internal air temperature. Differentiating the gas law with respect to $z$ (depth), we get

$$
\frac{d V_{i}}{d z}=-\frac{V_{i} T_{i}}{P_{i}} \frac{d}{d z}\left(\frac{P_{i}}{T_{i}}\right)
$$

Combining (24) and (25) and solving for $\varepsilon$ yields

$$
\varepsilon=\frac{V_{i} T_{i}}{\left(V_{g}-V_{h}\right) \rho g P_{i}} \frac{d}{d z}\left(\frac{P_{i}}{T_{i}}\right) .
$$

The dimensions of two hull sections of glider Coprolite were outer diameter $220 \mathrm{~mm}$, inner diameter $204 \mathrm{~mm}$, and length $475 \mathrm{~mm}$, so that $V_{h}=5.06 \mathrm{~L}$. The glider volume was set at $V_{g}=54.802 \mathrm{~L}$ (see also Fig. 7). The internal air volume was established at $31 \mathrm{~L}$ by weighing the glider with a scale (maximum weight $65 \mathrm{~kg}$ and 1-g precision) for a range of internal vacuum levels. The internal temperature sensor may overestimate the air temperature representative for the whole glider because of heat generated by the pump and batteries. The water temperature, on the other hand, may be too cold. Therefore, for practical reasons, $T_{i}$ is estimated by the average of the internal and external (water) temperatures.

Figure 11 shows a typical profile of the ratio $P / T$, where the $i$ subscripts have been dropped for the sake of convenience. At the surface, the value of $P / T$ is low because of an increased pressure as a result of the inflated air bladder. ${ }^{2}$ During the dive, the internal pressure increases as the hull compresses. When the pump is activated at depth, the internal reservoir is pressurized (to facilitate the pump), which results in a sudden drop of the internal pressure. When the pump is switched off,

\footnotetext{
${ }^{2}$ At the surface, the glider inflates an air bladder for additional buoyancy. The air is extracted from the glider internal: hence, the decrease in pressure.
}

the excess pressure on the bellows is released again. During the pumping, heat is generated, which becomes apparent by a small decrease in $P / T$ at the beginning of the climb. Because the heat is lost to the environment, the curve of $P / T$ becomes gradually linear with depth. The reason for $P / T$ being larger during the down cast than during the up cast is because of the increased internal volume from pumping out oil to the external reservoir.

To avoid temperature effects that occur directly after the onset of climbing and those that may occur after the onset of the first dive after surfacing, the rhs of (26) is evaluated for the range $-500<z<-300 \mathrm{~m}$, yielding an estimate for the compressibility for each up and down cast. The results for glider Coprolite are shown in Fig. 7, third panel. The (thin) solid and dashed lines are 1 day averages for the up and down casts, respectively. The order of magnitude found for both the up and down casts is the same and compares quite well with the compressibility found from the minimization procedure.

\section{Vertical water velocities}

It may be argued that finding a minimum in the cost function does not necessarily imply that the vertical water velocities corresponding to the optimal parameter settings show any agreement with the real vertical water velocities. Moreover, if parameters show unphysical time-varying behavior, to what extent does that influence the final result (i.e., the calculated vertical velocities)? To answer this question, the resulting vertical water velocities are analyzed in detail.

Two periods are highlighted. The first period is during the beginning weeks of the mission, 4-24 February 2008. Most of the vertical water motion will be in the form of internal waves, with vertical velocities on the order of $1-2 \mathrm{~cm} \mathrm{~s}^{-1}$, because (negative) heat fluxes had been very 


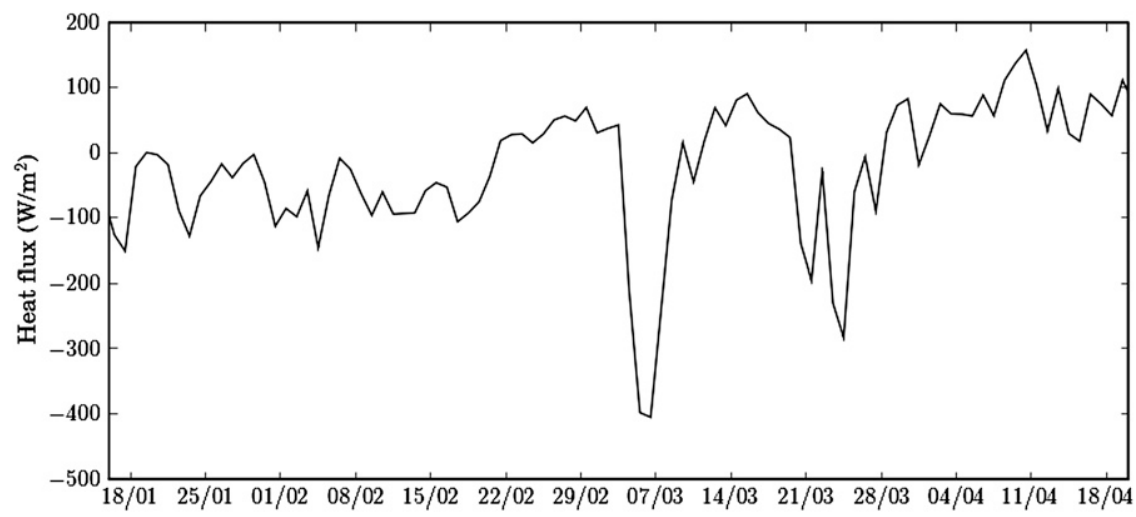

FIG. 12. Surface heat fluxes for the Gulf of Lions area (source: NCOF model).

low for a prolonged period of time (see Fig. 12). Cold spells occurred during a short period around 7 March and later for a slightly longer period, but less intense, around 22 March. During these two periods, one may expect the water column to become unstable by cooling of the surface layers. The resulting convection events are reported to be accompanied with strong vertical water motion, up to the order of $10 \mathrm{~cm} \mathrm{~s}^{-1}$ (see, e.g., Marshall and Schott 1999).

\section{a. Observations}

The measured vertical velocity $w_{p}$ inherits the highfrequency noise from the pressure transducer signal (see also section $4 \mathrm{c}$ ). When $w_{p}$ data are presented or used to calculate the vertical water velocity, the signal is first smoothed using a moving average filter with a (Hamming) window width of 21 samples, corresponding to a time window of about $80 \mathrm{~s}$.

Time series of vertical velocities measured on 24 February are shown in Fig. 13. The top panel shows the measured vertical velocity $w_{p}$ and the modeled velocity $w_{g}$ (both smoothed) by gray and thick solid lines, respectively. The resulting water velocity is shown in black (using the right-hand side ordinate). Comparing the measured and modeled vertical velocity, it appears that both series show the same features and look very similar. During its climb, the glider adjusted several times its center of gravity to adjust the pitch by moving a mass (9-kg battery pack) along the glider's main axis. These sudden changes have a distinct effect on the vertical speed of the glider. The spikes caused by moving the pitch battery pack do not appear in the water velocity, indicating that the adjustment time of the glider is smaller than the length of the smoothing window used $(80 \mathrm{~s})$.

Some spikes do occur in the vertical water velocity signal. From a comparison with the corresponding depth profile, it turns out that these spikes occur during the inflection points or when the glider is at the surface. The model is not valid when the glider is at the surface, and the quasi-steady flight assumption does not hold during the inflections. In further analyses, these data are not included.

The vertical water velocities have an order of magnitude of 1-2 $\mathrm{cm} \mathrm{s}^{-1}$ and could be due to internal waves. Later (in section $4 \mathrm{c}$ and Fig. 17), the buoyancy frequency at middepth is estimated at 1.5 cycles per hour (cph), so that an isopycnal oscillating at this frequency with an amplitude of about $10 \mathrm{~m}$ would yield the observed vertical velocities. The isopycnals computed from the temperature and salinity data shown in Fig. 6 seem to support this. Furthermore, no bias or drift is observed; a bias with equal sign for both the up and down casts indicates an error in the glider volume, and a bias with opposite signs for the up and down casts indicates an error in the drag coefficient. Also, the down casts or up casts do not show a particular pattern, which would be the case if the compressibility would be wrong. In conclusion, the minimization of the cost function seems to yield a good estimate for the three calibration parameters, yielding a signal that seems to be consistent between the up and down casts with continuous transitions.

Around 7 March, the surface heat loss was fairly strong (Fig. 12), and evidence of strong mixing of the water column during the same period is shown in Fig. 6. The mixing is caused by intense vertical motion with velocities on the order of $10 \mathrm{~cm} \mathrm{~s}^{-1}$, as mentioned earlier. To have confidence in the calculated vertical water velocities, the results should reflect the changes in physical forcing.

The vertical velocities for a one-day period around 7 March are shown in Fig. 14. The conclusions drawn from the previous time series also hold here, except that the resulting vertical water velocities are substantially larger. The magnitude of the velocity found at depth rarely exceeds $2 \mathrm{~cm} \mathrm{~s}^{-1}$; however, nearer to the surface, strong downward plumes can be detected, notably 
(a)

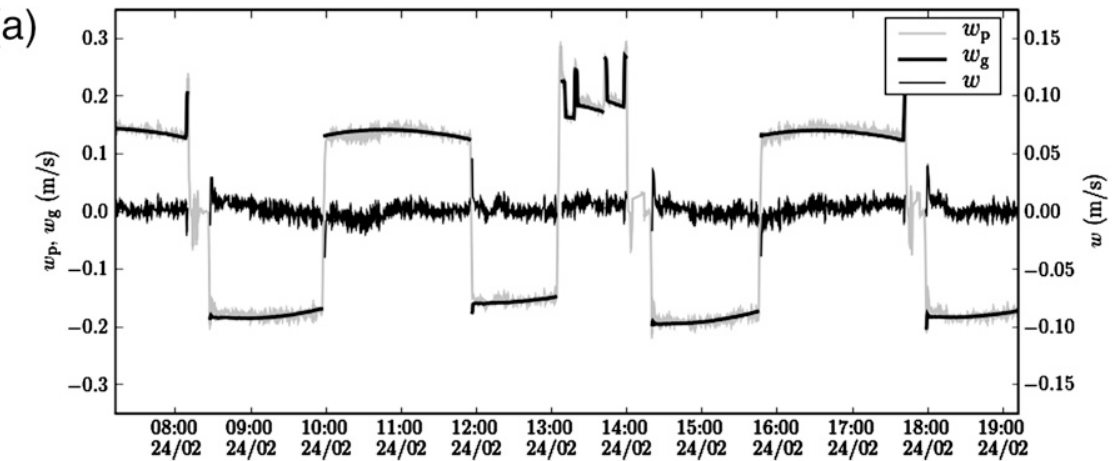

(b)

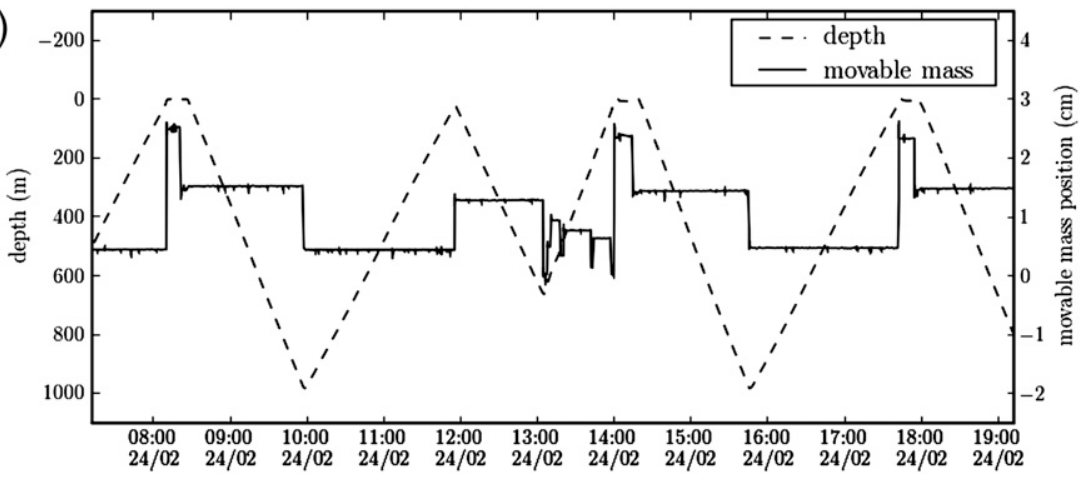

FIG. 13. Data for glider Coprolite measured on 24 Feb 2008: (top) vertical velocities and (bottom) the corresponding depth profiles.

around 0915 and 1530 UTC, with a magnitude of $8-10 \mathrm{~cm} \mathrm{~s}^{-1}$. This is in line with the expectation, because the kinetic energy of the water reduces with depth.

\section{b. Velocity histograms}

A typical feature of convection is that the downward plumes appear to have smaller horizontal dimensions than the upward plumes; however, as a consequence of mass conservation, the magnitude of the downward velocity is larger. Figure 15 shows histograms of observed vertical water velocities for periods of 3 days centered around 24 February and 7 March. To highlight the effects resulting from convection, only data for the upper $500 \mathrm{~m}$ are used, which captures the mixed layer for 7 March. The histogram for 24 February (left panel) is narrow compared to the histogram for 7 March (right panel), which is to be expected from the time series shown earlier. The histogram for 24 February is also more or less symmetric, in accordance with what would be expected in the case of internal waves. The histogram for 7 March, on the other hand, shows a clear asymmetry by a tail biased toward negative vertical velocities with downward velocities of $10 \mathrm{~cm} \mathrm{~s}^{-1}$, whereas the maximum upward velocity is about $5 \mathrm{~cm} \mathrm{~s}^{-1}$. The rms vertical velocity is $2.4 \mathrm{~cm} \mathrm{~s}^{-1}$. A velocity scale $w_{*}$ for convection is given by (Marshall and Schott 1999)

$$
w_{*} \propto(B h)^{1 / 3},
$$

where $B$ is the buoyancy flux, given by $B=g \alpha_{\gamma} H / C_{p} \rho$, and $h$ is the mixed layer depth. With a thermal expansion coefficient $\alpha_{\gamma}=2 \times 10^{-4} \mathrm{~K}^{-1}$ and heat capacity $C_{p}=$ $4200 \mathrm{~J}(\mathrm{~K} \mathrm{~kg})^{-1}$, the maximum buoyancy flux is about $2 \times 10^{-7} \mathrm{~m}^{2} \mathrm{~s}^{-3}$, giving $w_{*} \approx 4.5 \mathrm{~cm} \mathrm{~s}^{-1}$ for $h=500 \mathrm{~m}$, which is in a reasonable agreement with the observed rms value.

\section{c. Vertical velocity power spectrum}

The time series from 4 to 24 February, during which internal waves are expected to dominate the vertical velocity characteristics, is examined in terms of a power spectrum diagram. The time series is not sampled uniformly; gaps in the data occur when the glider is at the surface and $70 \%$ of the data is sampled at an interval of $4 \pm 0.01 \mathrm{~s}$, with the remaining $30 \%$ sampled at an interval between 4 and $5 \mathrm{~s}$. Although it is recognized that special techniques exist for Fourier transforming nonuniformly distributed data, the majority of the data is equidistant, so that, as a first approach, it seems fair to subsample the time series with a 4.0-s interval.

The estimate for the power density spectrum of the vertical velocity (solid line) as a function of the angular frequency $\omega$ is shown in Fig. 16. The spectrum is an 

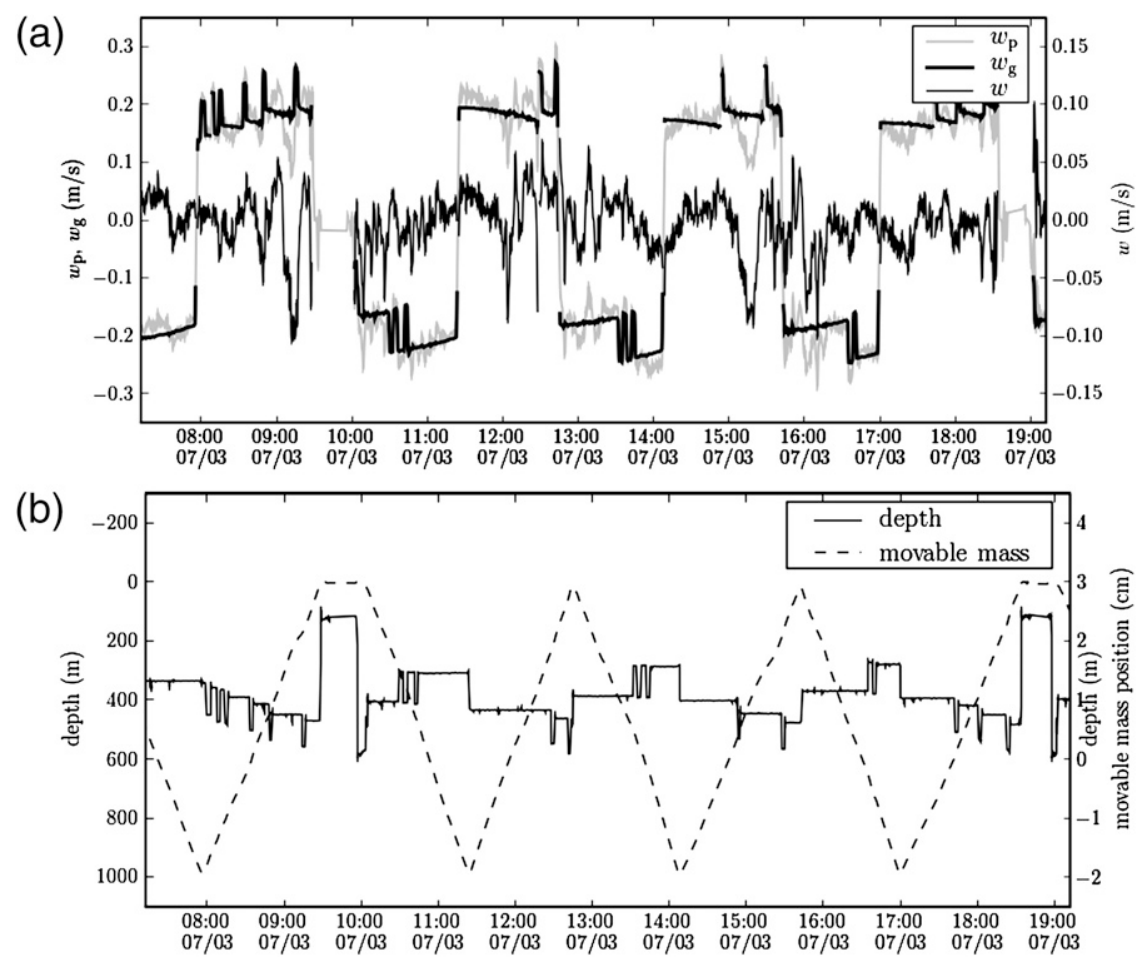

FIG. 14. Data for glider Coprolite measured on 7 Mar 2008: (top) vertical velocities and (bottom) the corresponding depth profiles.

average of 105 transformations of time series with a duration of about $4.5 \mathrm{~h}$ ( $2^{12}$ data points). The spectrum is characterized by high energy levels at high frequencies, indicating that from $\omega=0.07$ the signal gets increasingly dominated by noise with $\omega$ increasing. Furthermore, the spectrum attains a slope of $-5 / 3$ for $\omega=\{0.008,0.07\}$ $\mathrm{rad} \mathrm{s}^{-1}$, which is characteristic for the inertial subrange where turbulence is three-dimensional and isotropic (Tennekes and Lumley 1972). For lower values of $\omega$, the curve first steepens to a slope of -3 , to flatten for even lower frequencies.

To interpret the spectrum, first the buoyancy frequency is considered. A time-averaged potential density profile is shown in Fig. 17 (left) by the solid line. Except
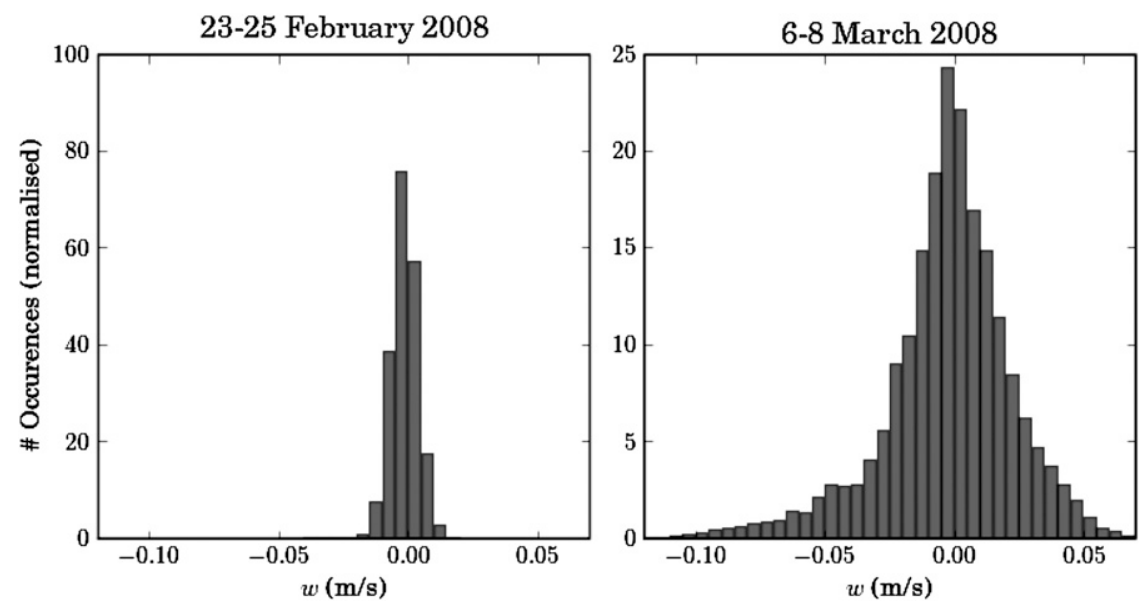

FIG. 15. Histograms of recorded vertical water velocities: results from (left) a 3-day period from 23 to $25 \mathrm{Feb} 2008$ (no convection) and (right) a 3-day period from 6 to 8 Mar 2008, during which convective events occurred. 


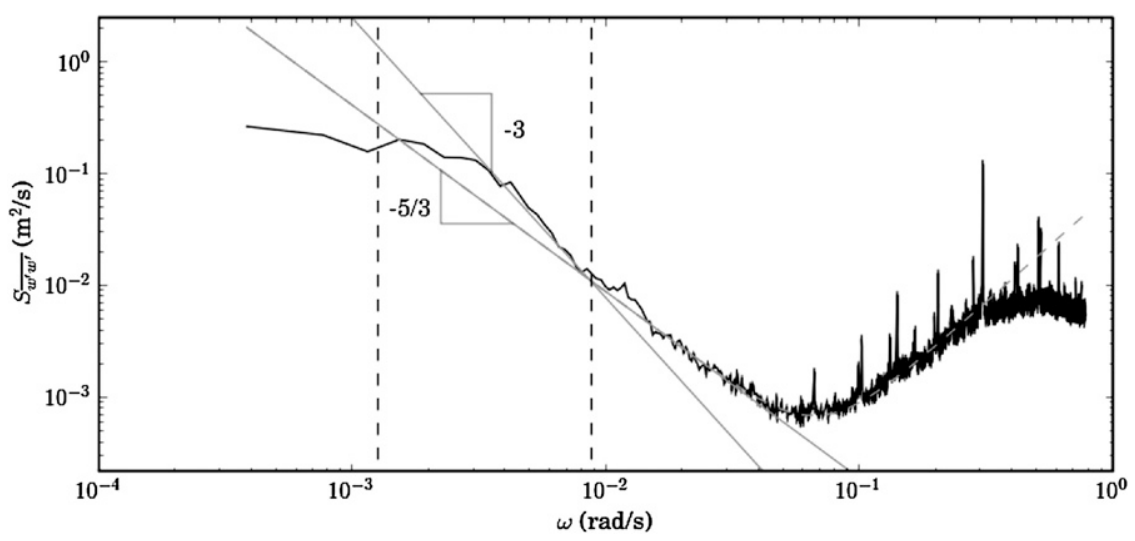

FIG. 16. Spectral power diagram of vertical velocities. The solid black line represents the power spectrum of the vertical water velocities. The gray lines represent the $-5 / 3$ and -3 slopes. The vertical dashed lines mark the maximum and minimum buoyancy frequencies observed in Fig. 17 (right).

for the upper $200 \mathrm{~m}$, little variation is observed between the individual data points (in gray) and the averaged value. The pertaining buoyancy frequency $N$, calculated as $N^{2}=-g / \rho_{0} d \rho / d z$, is shown in the right panel, showing that $N$ ranges from about $0.6 \mathrm{cph}$ at $1000-\mathrm{m}$ depth to $5 \mathrm{cph}$ near the surface. The maximum and minimum buoyancy frequencies are marked by the vertical dashed lines in the power spectrum. The maximum buoyancy frequency occurs almost exactly at the transition from the -3 to $-5 / 3$ slope. Physically, this corresponds to the fact the maximum frequency of internal waves is limited by the buoyancy frequency and thus no internal waves are present in the higher-frequency range. The minimum buoyancy frequency more or less marks the region where the energy starts to drop off toward a -3 slope.

\section{d. Estimate of accuracy}

Although lacking an independent measurement of the vertical velocities, the previous three subsections have presented robust but indirect evidence of the calculated vertical water velocities to be reasonably accurate. But, how accurate is "reasonable"?

To quantify the accuracy, we first look at the mean values. The mean values of the data shown in the histograms of Fig. 15 are found to be -1.8 and $-2.5 \mathrm{~mm} \mathrm{~s}^{-1}$. The mean value of the vertical velocity of the whole record amounts to $0.1 \mathrm{~mm} \mathrm{~s}^{-1}$. After the cost-function minimization, the mean values for 3 -day periods are $0.2 \pm$ $4 \mathrm{~mm} \mathrm{~s}^{-1}$. Calculating the mean values per depth bins of $50 \mathrm{~m}$, the variation is typically less than $0.1 \mathrm{~mm} \mathrm{~s}^{-1}$. Therefore, it seems that the systematic error in the vertical velocity is approximately $\pm 4 \mathrm{~mm} \mathrm{~s}^{-1}$.

As shown clearly in the power spectrum diagram (Fig. 16), sensor noise gradually builds up with $\omega$ increasing beyond about $0.07 \mathrm{rad} \mathrm{s}^{-1}$. The primary source of noise stems from the pressure sensor. The observed velocity signal $w_{m}$ can be decomposed as $w_{m}=w_{p}-w_{g}+$ $w_{\varepsilon}=w+w_{\varepsilon}$, where $w_{\varepsilon}$ is the noise component of the signal; $w_{\varepsilon}=d h_{\varepsilon} / d t$, where $h_{\varepsilon}$ is the noise in the depth reading. In frequency space, the Fourier transforms of $w_{\varepsilon}$ and $h_{\varepsilon}$ relate as $W_{\varepsilon}=i \omega H_{\varepsilon}$, so that for the observed signal we get

$$
\begin{aligned}
W_{m} W_{m}^{*} & =\left(W+i \omega H_{\varepsilon}\right)\left(W+i \omega H_{\varepsilon}\right)^{*} \\
& =W W^{*}+\omega^{2} H_{\varepsilon} H_{\varepsilon}^{*} .
\end{aligned}
$$

Note that the cross products depend on the (random) phases of the $w$ and $h_{\varepsilon}$, so that their contribution vanishes when many ensembles are used to estimate the power spectrum. Assuming white noise (i.e., $H H^{*}$ is constant) and noting that power spectra are proportional to the multiplication of the Fourier transform and conjugated Fourier transform of the signal, we find for the inertial subrange that the power spectrum of the measured signal relates as

$$
S_{\overline{w^{\prime} w^{\prime}}} \approx c_{1} \omega^{-5 / 3}+S_{\overline{h_{\varepsilon} h_{\varepsilon}}} \omega^{2},
$$

where $c_{1}$ is the proportionality factor and $S_{\overline{h_{\varepsilon} h_{\varepsilon}}}$ is the (constant) spectrum of the noise of the depth signal. Fitting (29) to the measured spectrum (gray dashed line), we find that $c_{1}=4.1 \times 10^{-6} \mathrm{~m}^{2} \mathrm{~s}^{-8 / 3}$ and $S_{\overline{h_{\mathrm{s}}}}=$ $0.07 \mathrm{~m}^{2} \mathrm{~s}$. The variance of the noise in the depth readings is approximately $S_{\overline{h_{h}}} \omega_{\max }$, giving an rms value of $23 \mathrm{~cm}$. The pressure sensor is rated for $2000 \mathrm{psi}^{3},{ }^{3}$ which corresponds to $1370 \mathrm{~m}$ of water pressure. The noise

\footnotetext{
${ }^{3}$ Taken from the glider configuration file autoexec.mi.
} 

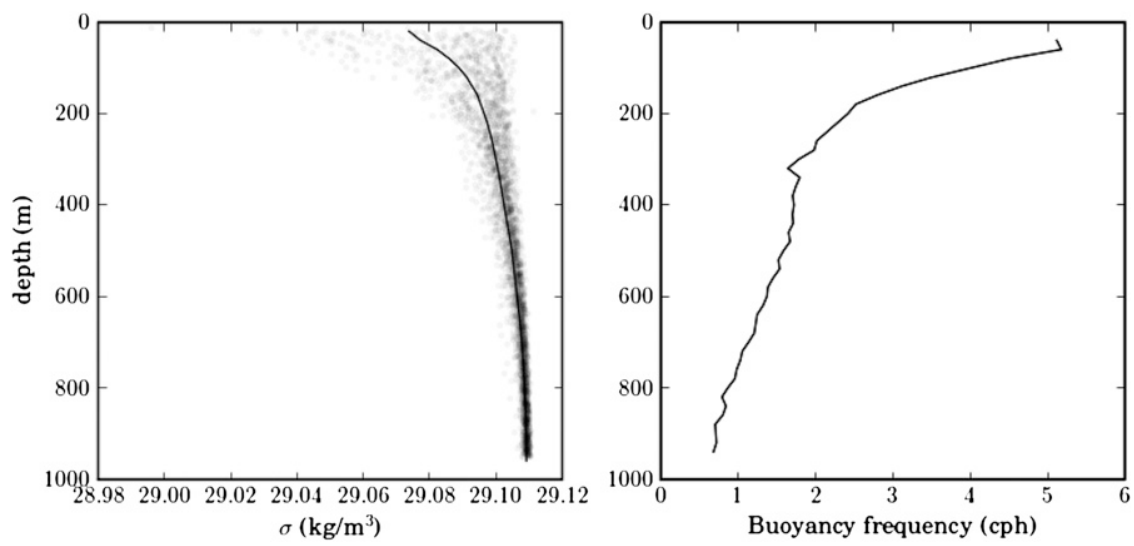

FIG. 17. (left) Time-averaged potential density profile as measured during the period from 4 to $24 \mathrm{Feb} 2008$ (solid line): the gray dots show $1 \%$ of the actual density measurements. (right) The buoyancy frequency $N$, calculated from $N^{2}=-g d \rho / d z / \rho_{0}$, is shown using the potential density profile shown in (left).

level in relation to the full scale of the pressure transducer then amounts to about $0.02 \%$. For comparison, the specification sheet of a more accurate SBE-52 transducer claims a pressure resolution of $0.002 \%$ (rated $3000 \mathrm{psi}$; see online at http://www.seabird.com/products/ spec_sheets/52data.htm).

The total variance of the velocity signal amounts to $0.005 \mathrm{~m}^{2} \mathrm{~s}^{-2}$, of which $80 \%$ is contributed by noise (signal-to-noise ratio is about 0.2 ). The rms value of $w_{\varepsilon}$ is calculated at $6.3 \mathrm{~cm} \mathrm{~s}^{-1}$, which is close to $h_{\mathrm{rms}} / \Delta T=$ $5.8 \mathrm{~cm} \mathrm{~s}^{-1}$, where $\Delta T$ is the sample time (4 s).

In practice, this means that the signal should be treated with a low-pass filter, with a cutoff frequency near $0.01 \mathrm{~Hz}$. As mentioned earlier, the vertical velocity data shown in the figures, except Fig. 16, were smoothed using a running averaging procedure that applies a Hamming window of 21 samples long. This means that the usable time resolution is about $80 \mathrm{~s}$ or about $20 \mathrm{~m}$, the vertical distance traveled by the glider within that time frame. In addition, on shorter time scales, the neglect of the acceleration terms also becomes questionable.

\section{Conclusions}

We have set up a quasi-static model for the glider dynamics to describe planar flight for the purpose of estimating vertical water velocities in the ocean along glider trajectories. The principle is that the vertical water velocity is the difference of the depth rate, as measured by the pressure sensor, and the modeled vertical velocity of the glider, assuming the glider flies in still water. The quasi-static model involves a number of parameters, of which most can be measured directly or parameterized. The (parasite) drag coefficient, com- pressibility, and glider volume are quantified by minimizing a cost function, based on the difference between pressure-derived and modeled glider velocities. In particular, the drag coefficient and the glider volume show physically unlikely variation in time. It has been pointed out that the buoyancy change, as reported by the glider, may be significantly different from the actual buoyancy change because of the presence of air bubbles in the oil system, the main component of the buoyancy engine. The observed variation in glider volume with time is most probably the result of the minimization procedure to compensate the effects caused by this discrepancy. The variation in drag coefficient probably has two origins: the presence of air bubbles in the oil system and also biofouling, which causes the drag to increase gradually.

Technical explanations as to why air can appear inside the oil system are glider specific and considered to be beyond the scope of this paper. Quantifying the effect of air is difficult: the air that is in the external reservoir is subjected to large pressure differences, affecting the amount of air in solution, the size of the bubbles, the transfer rate between internal and external reservoirs, etc. Including a torque balance and carefully accounting for changes in the center of mass resulting from moving oil between the internal and external reservoirs may be accurate enough to quantify the discrepancy in reported and actual buoyancy, but this is left for future work.

For practical reasons, no comparison could be made with vertical velocity data from an independent measurement technique, such as an acoustic Doppler current profiler. Applying the model to data gathered during the Gulf of Lions experiment in 2008 showed that the vertical water velocity has the character of internal waves 
during a period of weak surface heat fluxes. When applied to a (short) period of intense surface heat loss, the vertical water velocities have a velocity scale that is in agreement with scaling laws for active open ocean convection. These results strongly suggest that the variation observed for the calibration parameters compensate errors in input parameters, such as the buoyancy change, and this does not affect the final result: the vertical water velocities. The recommended period to apply the minimization of the cost function to is 1 day, which is long enough to provide sufficient data to minimize the cost function and short enough to capture the time variation of the parameters.

It appeared, however, that vertical velocity data contain a high level of noise, introduced by the pressure sensor. Meaningful vertical velocity data are obtained after applying a low-pass filter, such as an 80-s Hamming window. The absolute error in the velocity measurement is estimated at $\pm 4 \mathrm{~mm} \mathrm{~s}^{-1}$.

Acknowledgments. We thank IFREMER (La Seyne sur Mer, France) for the generous support during glider preparation, deployment, and recovery. We are grateful too to colleagues in the European Glider Observatories network, particularly Pierre Testor, for their generous exchange of practical help and knowledge on gliders. Pierre Testor and Laurent Mortier kindly provided data from glider Pytheas used to calculate the results presented in Fig. 8. We also thank Clayton Jones (Teledyne Webb Research Corp.) for sharing information on many technical aspects of the 1000-m Slocum glider and Harry Bryden, who stimulated our interest in measuring vertical velocity. The authors are grateful for financial support form the U.K. Natural Environment Research Council under Grant NE/B505911/1.

\section{REFERENCES}

Anderson, J. D., Jr., 2005: Introduction to Flight. McGraw-Hill, $814 \mathrm{pp}$.

Eriksen, C., T. Osse, R. Light, T. Wen, T. Lehman, P. Sabin, J. Ballard, and A. Chiodi, 2001: Seaglider: A long-range autonomous underwater vehicle for oceanic research. IEEE J. Oceanic Eng., 26, 424-436.

Etkin, B., and L. Reid, 1996: Dynamics of Flight: Stability and Control. 3rd ed. John Wiley and Sons, 382 pp.

Graver, J. G., 2005: Underwater gliders: Dynamics, control and design. Ph.D. thesis, Princeton University, 292 pp.

Griffiths, G., L. Merckelbach, and D. Smeed, 2007: On the performance of three deep-diving underwater gliders. Proc. OCEANS 2007-EUROPE, Aberdeen, Scotland, IEEE, 59-63.

Hayes, D., and J. Morison, 2002: Determining turbulent vertical velocity, and fluxes of heat and salt with an autonomous underwater vehicle. J. Atmos. Oceanic Technol., 19, 759-779.

Jones, C., E. Creed, S. Glenn, J. Kerfoot, J. Kohut, C. Mudgal, and O. Schofield, 2005: Slocum gliders-A component of operational oceanography. Proc. 14th Int. Symp. on Unmanned Untethered Submersible Technology, Lee, NH, Autonomous Undersea Systems Institute.

Marshall, J., and F. Schott, 1999: Open-ocean convection: Observations, theory, and models. Rev. Geophys., 37, 1-64.

Sherman, J., R. Davis, W. Owens, and J. Valdes, 2001: The autonomous underwater glider "Spray." IEEE J. Oceanic Eng., 26, 437-446.

Stommel, H., 1989: The Slocum mission. Oceanography, 2, 22-25.

Tennekes, H., and J. Lumley, 1972: A First Course in Turbulence. MIT Press, $300 \mathrm{pp}$.

Williams, C., R. Bachmayer, and B. deYoung, 2007: Prediction of the performance of ocean gliders. Proc. 15th Int. Symp. on Unmanned Untethered Submersible Technology, Durham, $\mathrm{NH}$, Autonomous Undersea Systems Institute. 